\title{
MET Gene Deletion
}

National Cancer Institute

\section{Source}

National Cancer Institute. MET Gene Deletion. NCI Thesaurus. Code C147081.

A molecular abnormality referring to the loss of at least one copy of the MET gene. 